\title{
Structural and mechanical evaluations of a topology optimized titanium interbody fusion cage fabricated by selective laser melting process
}

\author{
Chia-Ying Lin, ${ }^{1,2,3}$ Tobias Wirtz, ${ }^{4}$ Frank LaMarca, ${ }^{1}$ Scott J. Hollister ${ }^{2,3,5,6}$ \\ ${ }^{1}$ Spine Research Laboratory, Department of Neurosurgery, The University of Michigan, Ann Arbor, Michigan \\ ${ }^{2}$ Scaffold Tissue Engineering Group, The University of Michigan, Ann Arbor, Michigan \\ ${ }^{3}$ Department of Biomedical Engineering, University of Michigan, Ann Arbor, Michigan \\ ${ }^{4}$ Fraunhofer Institute of Laser Technology, Aachen, Germany \\ ${ }^{5}$ Department of Mechanical Engineering, University of Michigan, Ann Arbor, Michigan \\ ${ }^{6}$ Department of Surgery, University of Michigan, Ann Arbor, Michigan
}

Received 31 January 2006; revised 25 August 2006; accepted 9 December 2006

Published online 5 April 2007 in Wiley InterScience (www.interscience.wiley.com). DOI: 10.1002/jbm.a.31231

\begin{abstract}
A topology optimized lumbar interbody fusion cage was made of Ti-Al6-V4 alloy by the rapid prototyping process of selective laser melting (SLM) to reproduce designed microstructure features. Radiographic characterizations and the mechanical properties were investigated to determine how the structural characteristics of the fabricated cage were reproduced from design characteristics using micro-computed tomography scanning. The mechanical modulus of the designed cage was also measured to compare with tantalum, a widely used porous metal. The designed microstructures can be clearly seen in the micrographs of the micro-CT and scanning electron microscopy examinations, showing the SLM process can reproduce intricate microscopic features from the original designs. No imaging artifacts
\end{abstract}

from micro-CT were found. The average compressive modulus of the tested caged was $2.97 \pm 0.90 \mathrm{GPa}$, which is comparable with the reported porous tantalum modulus of $3 \mathrm{GPa}$ and falls between that of cortical bone (15 $\mathrm{GPa})$ and trabecular bone $(0.1-0.5 \mathrm{GPa})$. The new porous Ti-6Al-4V optimal-structure cage fabricated by SLM process gave consistent mechanical properties without artifactual distortion in the imaging modalities and thus it can be a promising alternative as a porous implant for spine fusion. (c) 2007 Wiley Periodicals, Inc. J Biomed Mater Res 83A: 272-279, 2007

Key words: interbody fusion cage; topology optimization; titanium alloy; selective laser melting; porous tantalum

\section{INTRODUCTION}

The use of interbody fusion cages as an adjunct to spinal arthrodesis has become prevalent for a variety of pathological spine disorders in the last decade. Clinical outcome has been successful after short-term follow-up evaluation. However, many still agree that the long-term effects of cage devices on the motion segment still remain unclear despite these initial good results. ${ }^{1-7}$ The role of conventional interbody fusion cages has been mainly focused on providing immediate strength to maintain disc height and

Correspondence to: C.-Y. Lin; e-mail: lincy@umich.edu Contract grant sponsor: NIH; contract grant numbers: DE13608 (Bioengineering Research Partnership), DE13416

(C) 2007 Wiley Periodicals, Inc. shielding bone grafts from large mechanical forces within the cage to allow for bony healing. Therefore, conventional designs for cage devices are either cylindrical or wedge shaped with thick shells as outer walls and a hollow interior space that contains grafting materials. ${ }^{8}$ However, excessive cage rigidity may be associated with increased incidence of postoperative complications such as stress-shielding, the migration or dislodgement of the cage, pseudoarthrodesis, or combined adverse symptoms. ${ }^{5}$ The stress-shielded environment due to excessive stiffness of metallic cage devices compared to the motion segments and vertebral bodies allow lower intracage pressure propagation, ${ }^{9}$ which leads to subsequent decreased mineralization, bone resorption, and significant bone mineral density decrease in long term. $^{10}$

Enormous progress has been made in the development of biodegradable osteosyntheses to offer 
numerous major advantages over traditional metallic implants, one of which is the reduction of stress-shielding because of material compliance so that functional forces can be transferred to regenerate bone tissue to achieve a better healing. ${ }^{11,12}$ However, many still believe that metallic biomaterials can withstand physiological loads in both short and long term and thus they are more suitable for the development of implants for load bearing applications such as spine arthrodesis. To better match bone stiffness for avoidance of stress shielding, and to deliver osteobiological materials, high porosity is required in processing metallic biomaterials. One example of a material designed to meet this need is porous tantalum. Porous tantalum is fabricated via a chemical vapor infiltration (CVI) process that forms a reticulated vitreous carbon (RVC) skeleton, which is then encased by the precipitation of tantalum metal. ${ }^{13,14}$ The material is comprised of $75-85 \%$ void space and is characterized by interconnected unit cells that possess dodecahedron geometry. Despite this breakthrough, for processing a metallic biomaterial, significant batch-by-batch variation of mechanical properties of porous tantalum were recently found from the mechanical testing because of differences in morphology and processing. ${ }^{14}$ This inconsistency can be attributed to the less precise control on microstructural features such as thickness and structural arrangement. Porous Nitinol has also aroused recent interest for medical device applications, but more research may be required to better understand its nature for physical performance. $^{15}$

We reported previously our development for a new design approach for lumbar spine interbody fusion cages by using topology optimization algorithms to define the structural layout and inner microstructures. ${ }^{16}$ A suitable design for spinal fusion cages needs to address three major criteria: (1) limited displacements for stability, (2) sufficient strain energy density transfer to ingrown bone to reduce stress shielding, and (3) desired porosity for tissue ingrowth and biofactor delivery. Conventional designs ${ }^{1,2,9}$ may not be able to meet the multiple design requirements necessary to achieve sufficient rigidity, reduced stress shielding, and large porosity for biofactor delivery. Topology optimization $^{17,18}$ is a design technique that provides optimal distribution of material under applied force to satisfy the objective of maximal stiffness with desired porosity, under constraints of the three design criteria. This approach addresses the conflicting design issues of having sufficient stability while at the same time having enough porosity to deliver biofactors like cells, genes, and proteins and impart sufficient mechanical strain to maintain developing tissue. The interior architecture consists of micro- structures with reserved channel spaces for potential cell-based therapies and drug delivery. The interconnected microstructural struts form a network of load transmission so that the strain energy is absorbed by appositional bone at the cage/body interface as well as by regenerate tissue inside the cage. Thus, the three major design criteria considered were providing initial stability, reducing longterm stress shielding, and providing porosity for biofactor delivery.

In the present study, we demonstrate the capability to carry out the topology optimized design for lumbar interbody fusion cages made of Ti-6Al-4V alloy by utilizing a rapid prototyping process, selective laser melting (SLM), to achieve the designed spatial arrangement of material and reproduction of designed features of microstructures. In addition, radiographic and imaging characterizations as well as the mechanical properties from both compression test and finite element analysis (FEA) are conducted and the data are compared with those from previous clinical investigations using porous tantalum implants for spine interbody fusion.

\section{MATERIALS AND METHODS}

\section{Overview of integrated topology optimization design}

Topology optimization algorithms ${ }^{17,19,20}$ generate an optimized material distribution for a set of loads and constraints within a given design space, defined by solid finite elements. The topology optimization algorithm determines the material layout that gives the stiffest structure possible under both volume fraction and displacement constraints. Two rectangular block design spaces were used to represent the location of the implanted cages between vertebrae. Multi-directional physiological loads including compression, lateral bending, torsion, and flexion-extension were applied to the entire vertebral model as mentioned previously. ${ }^{16}$ This hierarchical macroscopic or first scale topology optimization solution that provides the general density and location of material within the design domain is then discretized into finite elements, and each element will contain a predicted material density between 0 and 1 . A material density value of 0 indicates void space while a value of 1 indicates complete material; values in between indicate partial material with the corresponding volume fraction. The resolution of the global topology design is too coarse, however, to give the specific microstructure that will be located within that point of the scaffold. Furthermore, since we would like the microstructure to have specific elastic properties at a fixed porosity, homogenization based topology optimization is used to design the microstructure. ${ }^{21,22}$ The microscopic or second scale topology optimization approach gives the specific microstructure design that achieves a desired compliance while matching the predicted volume fraction of the macroscopic or 1st level topology optimization. 


\section{Selective laser melting process for cage fabrication}

The selective laser melting (SLM) process (Fraunhofer ILT, Aachen, Germany) has been developed in recent years to overcome the limitation of the powder bed based generative manufacturing processes (so called rapid prototyping) that use a specific material or material composition resulting in insufficient mechanical properties. The material used in SLM is a single component metal powder like stainless steel $\mathrm{X} 2 \mathrm{CrNiMo17-13-2,} \mathrm{tool} \mathrm{steel}$ X38CrMoV5-1, Titanium GdII or Titanium Ti-6Al-4V. In addition, the physical process is complete melting of a powder layer with metallurgical bonding between layers, which yields densities close to $100 \%$ in one step. These characteristics enlarge the field of applications for this technology from Rapid Prototyping to the Rapid Manufacturing of functional parts such as the intricate spinal cage presented from the design of integrated topology optimization. $^{23}$

In the current investigation, $\mathrm{Ti}-6 \mathrm{Al}-4 \mathrm{~V}$ powder was selected with a particle size of $25-45 \mu \mathrm{m}$ as basic material to conduct the designed spine cage fabrication. The image data of the designed cage were converted to a surface representation in stereolithography format (.STL). Like all other generative manufacturing processes, the 3-D computer aided design (CAD) model was then sliced into layers with defined thickness. In this case, the dimension of our designed cage is $24.5 \mathrm{~mm}(\mathrm{~L})$ by $14 \mathrm{~mm}(\mathrm{~W})$ by $14 \mathrm{~mm}(\mathrm{H})$, which is composed of $3.2 \mathrm{~mm}$ by $3.2 \mathrm{~mm}$ by $3.2 \mathrm{~mm}$ microstructures with the minimal feature size of $500 \mu \mathrm{m}$. Using the commercial software (VisCam SLM v1.97, Paderborn, Germany), the CAD model of the cage was raised up $2 \mathrm{~mm}$ high and then was supported by thin wall structures to enable the cage to be released from the substrate after its build-up. It was then sliced into 534 layers. The layer thickness used for the fabrication of the spinal cage was $30 \mu \mathrm{m}$ that provides a reasonable balance between geometric accuracy, surface quality, and fabrication time. The actual parts were generated on a modified F\&S (Fockele \& Schwarze) fabrication system by repeating the process of applying new material layers and subsequently scanning the area and the contour with the laser beam from Nd:YAG-solid state laser system offering $130 \mathrm{~W}$ optical power onto overlapping tracks (Fig. 1).

\section{Radiographic and imaging characterizations}

Five samples with volume fracations of $52 \%$ were fabricated, scanned, and characterized by a MS-130 high resolution Micro-CT Scanner (GE Medical Systems, Toronto, Canada) at $27.2 \mu \mathrm{m}$ resolution using $2 \times 2$ binning $(120 \mathrm{kVp}$, $100 \mathrm{~mA})$. Volumes of each fabricated cage were measured using MicroView v 1.1.1 (GE Medical Systems, London, Ontario) and the scanned features were also compared with the original design by registering corresponding 3-D reconstructed images from standard micro-CT DICOM slides in a commercialized image process software, Analyze 5.0 (Biomedical Imaging Resource, Mayo Foundation, Rochester, MN). Macrostructural topology, microstructural

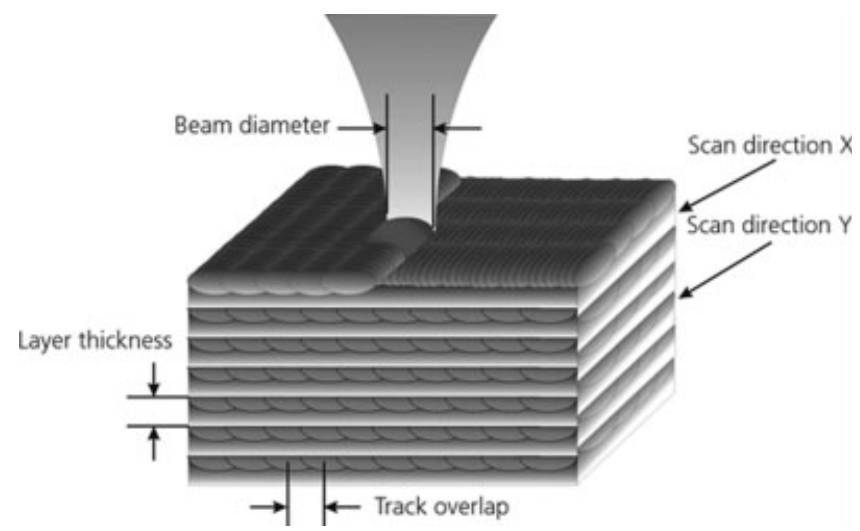

Figure 1. Schematic process of selective laser melting (SLM) fabrication technique.

features, and morphology of Titanium Alloy Ti-6Al-4V were also investigated by scanning electron microscopy (SEM).

\section{Mechanical testing}

Axial compression tests were performed to measure construct stiffness. A $4.45 \mathrm{~N}$ preload was applied followed by a compressive test to failure at a crosshead speed of $1 \mathrm{~mm} / \mathrm{min}$ [American Society for Testing and Materials (ASTM) D695-02a] using a MTS Alliance RT30 Electromechanical Test Frame (MTS Systems, MN). The compression test was continued, until the set break point of 20,462 N was met in the real-time compressive load-displacement curve, since the failure load of tested samples made of Ti$6 \mathrm{Al}-4 \mathrm{~V}$ alloy was estimated beyond the maximum load of $22,261 \mathrm{~N}$ of the default load cell of the testing system that is mainly designated for the biological tissue testing. Load versus deflection was continuously monitored and recorded, and stress-strain curve was generated based on geometrical parameters of samples. Effective compressive moduli defined as the slope of the linear region at the stress-strain curve were then calculated by the system.

To further characterize the ultimate compressive strength of the designed cage, two cages were subjected to more destructive loads at a rate of $0.25 \mathrm{~mm} / \mathrm{min}$ until they reached catastrophic failure using an Instron Floor Model Testing System (Instron, MA) with $150 \mathrm{kN}$ loading capacity.

Microhardness test was also conducted on a sandblasted cross section of the fabricated cages with a static indentation made with the load of $9.81 \mathrm{~N}$. The Vickers diamond pyramid indenter and precision microscopes (magnifications $10 \times$ and $40 \times$ ) in a microhardness tester (Buehler, Lake Bluff, IL) were used to measure the indentations for the calculation of the hardness.

\section{Image-based finite element analysis}

An image-based approach was used to deal with the enormously large-scale problem generated by complex 3-D geometries of the designed cages for the FEA simulating 


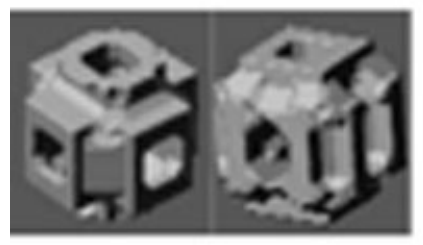

A

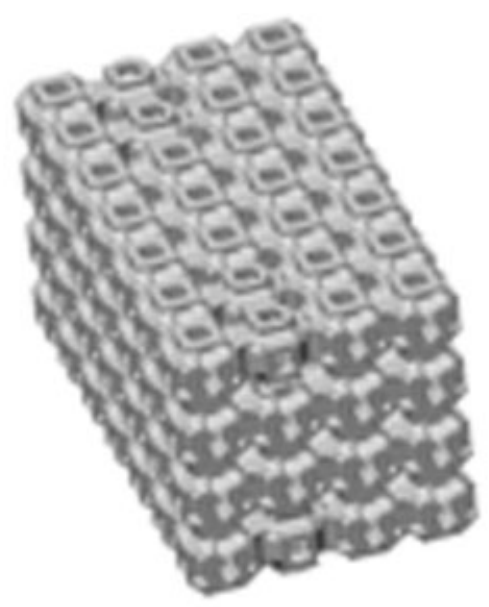

B

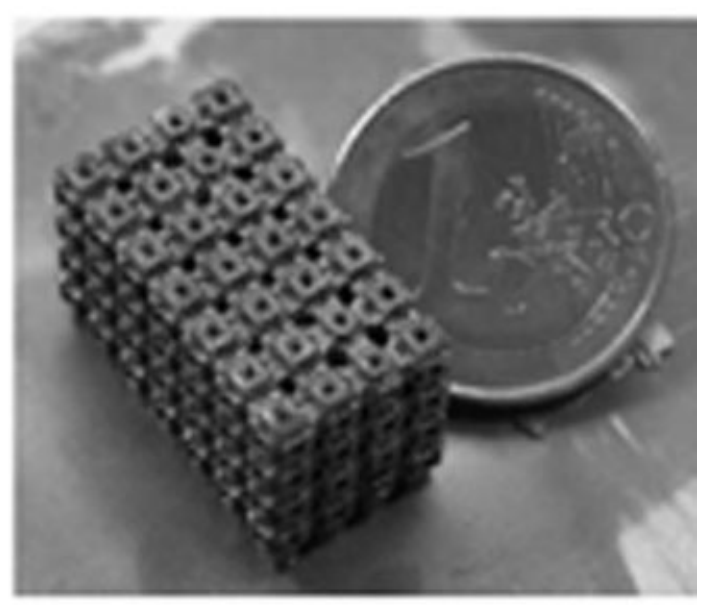

C

Figure 2. A: Designed microstructures by the topology optimization with volume fractions of $35 \%$ (left) and $55 \%$ (right). B: The three-dimensional volumetric image represented in .STL format of Optimal-Structure (OS) cage with total volume fractions of $52 \%$ and the dimension of $14 \mathrm{~mm}$ by $14 \mathrm{~mm}$ by $24.5 \mathrm{~mm}$. C: The fabricated titanium alloy cage.

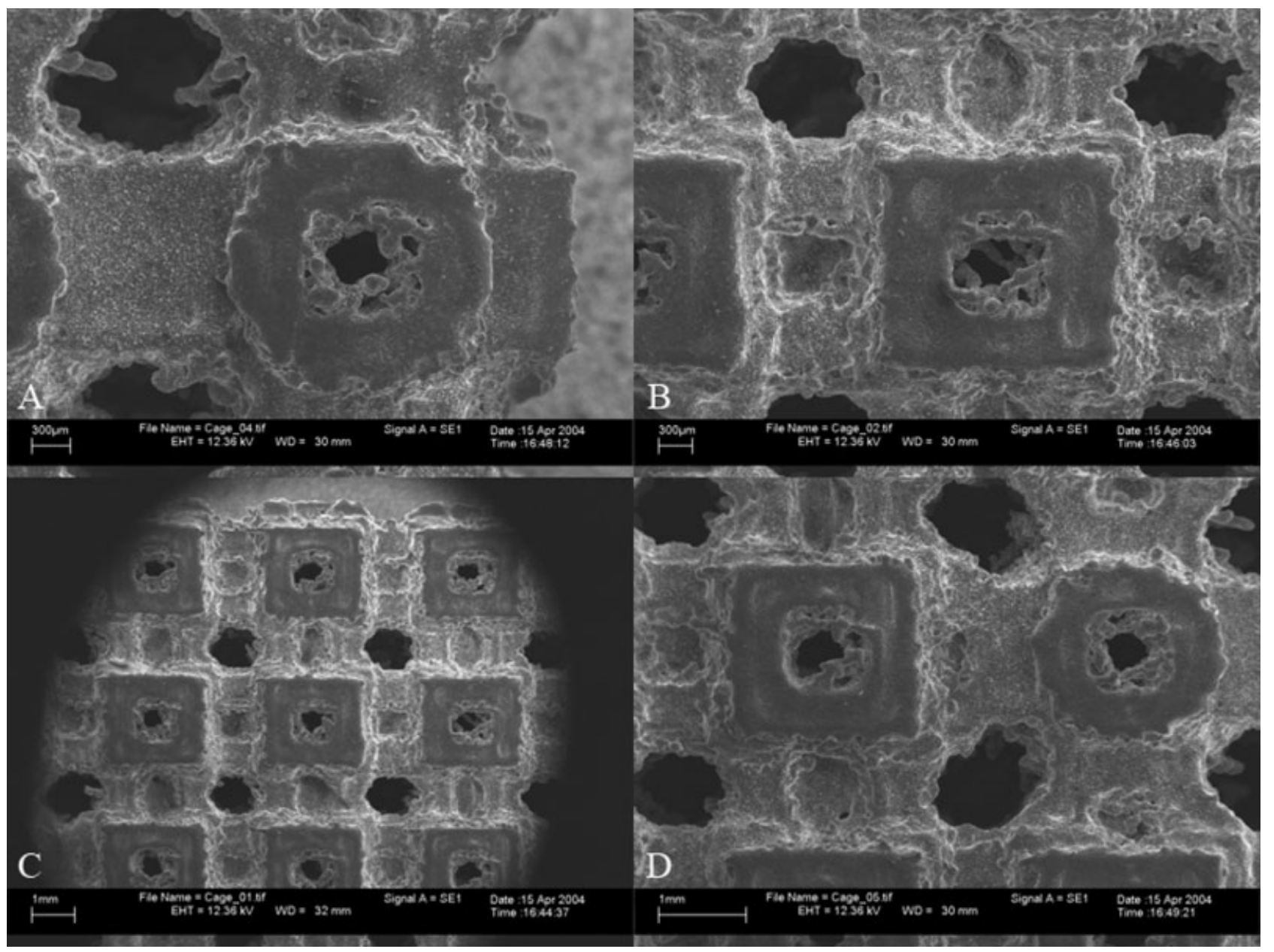

Figure 3. Micrographs showing microstructural features of fabricated titanium alloy Optimal-structure (OS) cage. A: The microstructure of a single unit cell with a volume fraction of $35 \%$. B: The microstructure of a single unit cell with a volume fraction of $55 \%$. C: The periodic interconnected microstructures of the design for 55\% volume fraction. D: The connected microstructures with different designs. 
the compression test in the present study. Image-based approaches allow very accurate replication of the design details, a characteristic not possible with the coarser traditional meshes. The concept of image-based FEA is simply to first convert the designed cage model in .STL format into a three-dimensional voxel dataset and then convert the voxels to finite elements. After the assignment of the material properties according to the grayscale levels to respective components and definition of the boundary conditions for cases of interest, the resulting model is solved using large-scale iterative algorithms. In this case, a Young's modulus of 118 GPa for post-SLM annealed Ti$6 \mathrm{Al}-4 \mathrm{~V}$ based on a previous report ${ }^{24}$ was assigned in the model and the fixed end was applied to the inferior surface of the cage, while a 1-mm displacement was applied on the superior surface. All aspects of the voxel finite element modeling process, including pre/post processing and analysis were performed using the commercial voxel finite element package Voxelcon (Quint, Tokyo, Japan).

\section{RESULTS}

The corresponding microstructures for volume fractions of 35 and 55\% [Fig. 2(A)] as reported previously ${ }^{16}$ were assigned to the global density layouts to complete the final design. The three-dimensional volumetric .STL image of the topology optimized design denoted as the optimal-structure (OS) cage with total volume fractions of $52 \%$ is shown in Figure 2(B). The fabricated cage shown in Figure 2(C) demonstrates the final product from the original design with dimensions of $14 \mathrm{~mm}$ by $14 \mathrm{~mm}$ by $24.5 \mathrm{~mm}$. The designed microstructures can be clearly seen in representative micrographs of the SEM examination of fabricated cages shown in Figure 3. Figure $3(\mathrm{~A}, \mathrm{~B})$ show the microstructures of a single unit cell with volume fractions of 35 and 55, respectively. Figure $3(\mathrm{C})$ shows the periodic interconnected microstructures of the design for 55\% volume fraction. Note that features of the microstructures are preserved from the design, giving an interconnected porosity resulting from integration of the designed local microstructure with the macroscopic density layout. Even between different designed microstructures, a bonded connection is seen, eliminating concern of weak interfaces commonly existing in materials with multi-phasic properties [Fig. 3(D)]. The reticulated micro-architecture of the tantalum implant on the other hand presented a well interconnection among each cell that constituted the porous structure within the global domain [Fig. 4(A)]. However, the pore size, volume fraction, and geometry varied due to the CVI process [Fig. 4(B)].

When registered with the original design, the micro-CT scanned images from fabricated cages showed that the designed features were able to be reproduced by the SLM process, but the variation

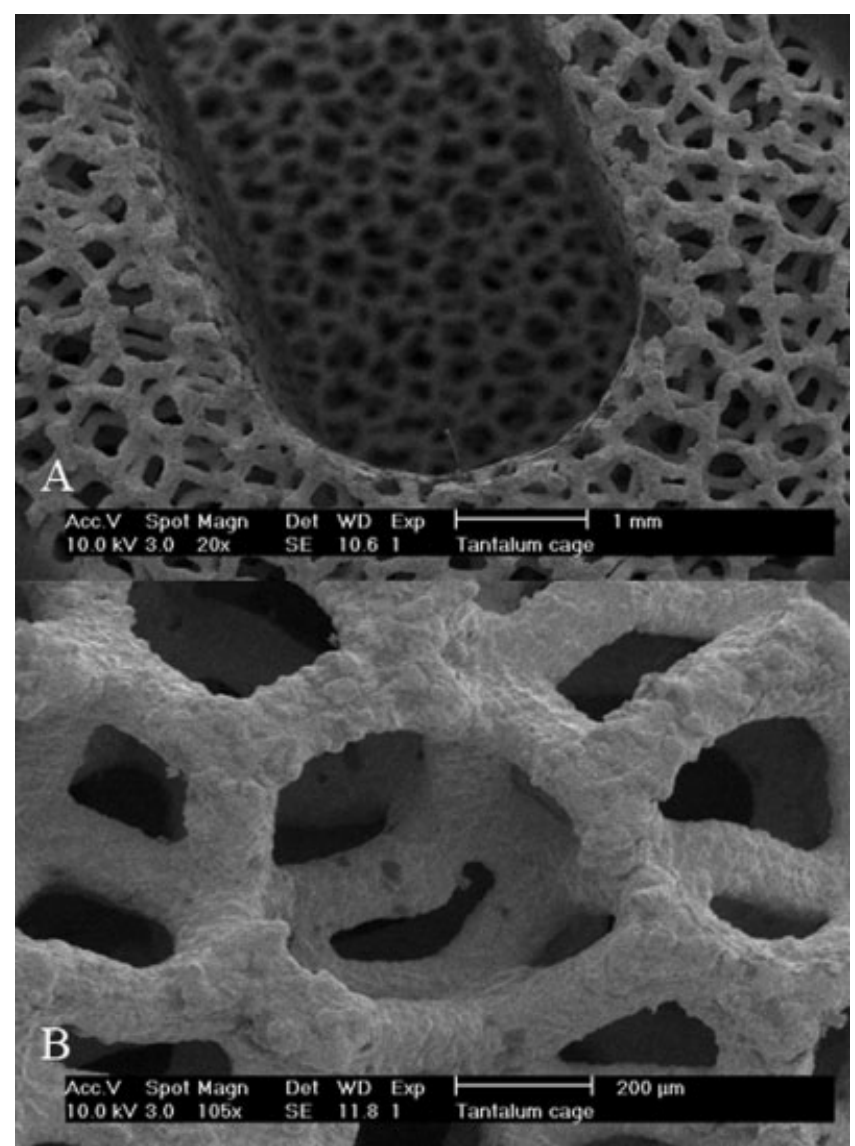

Figure 4. Micrographs from SEM showing microstructure of a tantalum cervical implant. A: Reticulated micro-architecture constituted with unit cells processed by chemical vapor infiltration. B: Microstructures with varied pore size, volume fraction, and geometry.

compared to the original design was also obvious (Fig. 5). The minimal feature size of the cage is $500 \mu \mathrm{m}$ at the finest struts of the designed microstructure, and these struts were reproduced successfully. However, the pore size of the designed channels within both microstructures is around $1000 \mu \mathrm{m}$, but the actual sizes of these pores from the fabricated cages were reduced to $\sim 700 \mu \mathrm{m}$. The rims of the pores were thickened in the range of $150 \mu \mathrm{m}$, which was caused by excessive sintering of Ti-6Al-4V powder during SLM process. The pores remained continuous, but the inner surface of the pores appeared irregular with some structural protrusion into the pore lumens, as shown consistently in a previous study. ${ }^{24}$ The result was also reflected on the volume in which the average volume of the fabricated cages was $2840.68 \pm 100.78 \mathrm{~mm}^{3}$ taking $(59.16 \pm 0.02) \%$ volume fraction, which was higher than the design volume of $2497.04 \mathrm{~mm}^{3}$ taking 52\% volume fraction. In all, the image characterization indicates that the fabrication of OS cage by SLM process was considered successful and the process can reproduce intricate microscopic features from the original designs, 

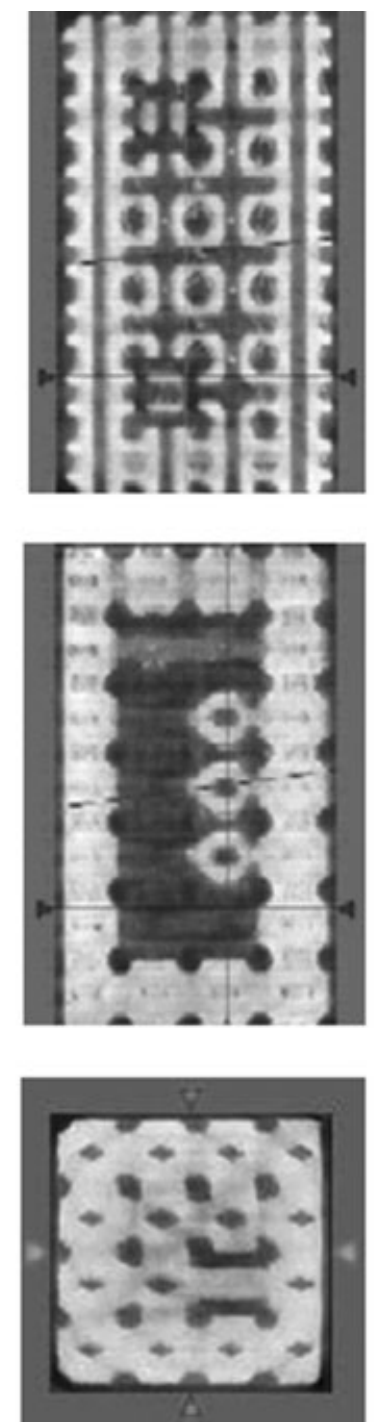
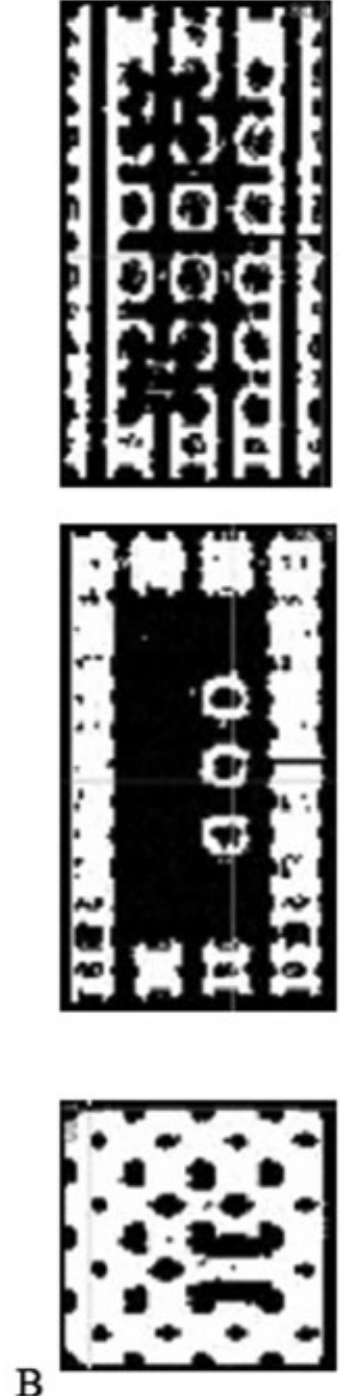
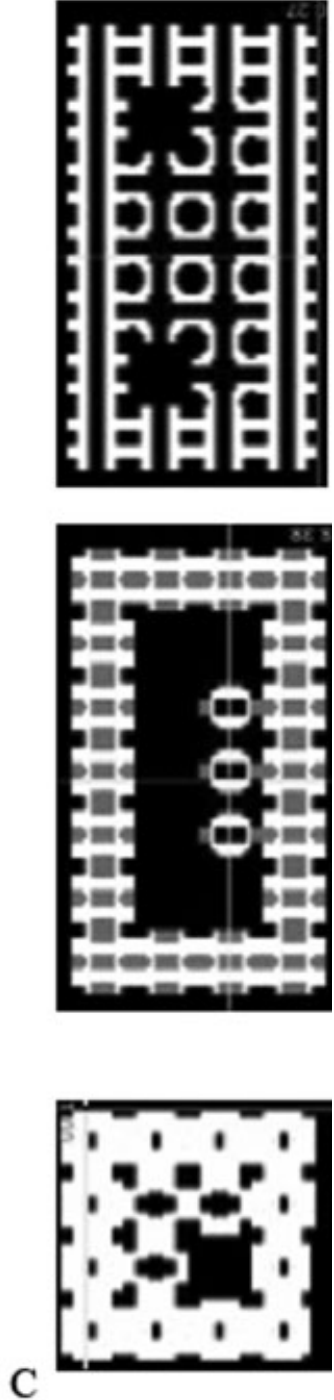

Figure 5. Comparisons of image slices from the designed cage (A) the micro-CT scan and (B) the registered scanned images with $(\mathrm{C})$ the original design (top to bottom: $X_{-}, Y_{-}$, and Z-axis).

even with complex architecture such as optimized topology.

The modulus for compression testing of fabricated cages was given by the slope of the stress-strain curve on the testing samples (Fig. 6). The stressstrain curve showed that the compressive moduli of the tested cages were consistent, indicating the fabrication process could achieve constant reproduction of the designed features and retain the consistency of mechanical performance of the designed implants. The average compressive modulus of the tested OS cage was $2.97 \pm 0.90 \mathrm{GPa}$, and the ultimate compressive load that caused the destructive failure of cages was $88.94 \pm 1.28 \mathrm{kN}$ and the ultimate compressive strength of tested cages $794.07 \pm 11.42 \mathrm{MPa}$. However, the computed effective compressive modulus from the FEA of the compression simulation is $5.5 \mathrm{GPa}$, which is almost as twice that calculated from the actual compression test.
The average Vickers hardness obtained from microhardness tests on the blasted surface of the fabricated cage is $303.461 \pm 16.019 \mathrm{Hv}$, which is $\sim 87 \%$ of the range $(349 \mathrm{Hv})$ of the medical grade, annealed Ti$6 \mathrm{Al}-4 \mathrm{~V}$ alloy according to ASTM standards. ${ }^{25}$

\section{DISCUSSION}

Metallic implants have been frequently used in the spine to enhance segmental stability, correct deformity, and deliver graft materials. Postoperatively, high-quality image examinations are required to investigate the effectiveness of the implantation such as the position of the implants and evaluate the developing status of surrounding anatomic structures. To this point, it is necessary to notice whether the materials used will interfere with the visualiza- 


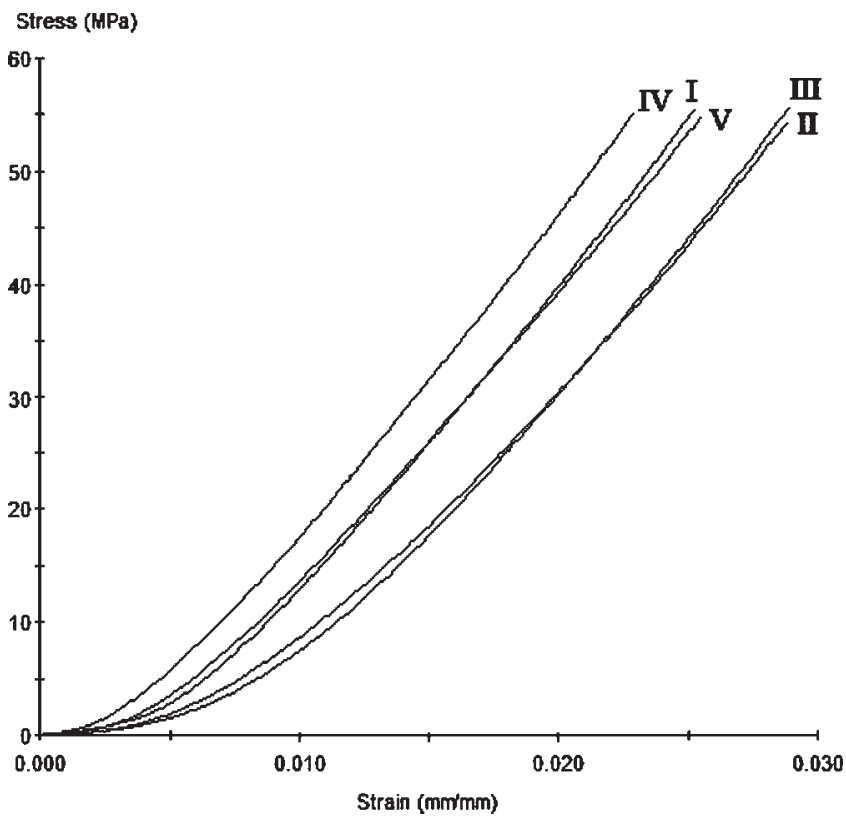

Figure 6. The stress-strain curves correspond to the testing samples (I to V) of fabricated titanium alloy OptimalStructure $(\mathrm{OS})$ cages $(n=5)$.

tion and assessment of the degree of arthrodesis and the integrity of the spinal canal and neural foramina because of the artifact generated on MR imaging and CT scanning.

Tantalum, a rare heavy metal with an atomic number of 73 and an atomic weight of 180.95, has been used for a variety of medical applications for over 50 years for high biocompatibility, high mechanical performance, resistance to corrosion, and biological inertness. ${ }^{26-28}$ Porous tantalum composed of $98 \%$ tantalum and $2 \%$ vitreous carbon has been recently introduced in orthopaedic applications and direct osseous apposition with the metal are observed, resulting in a strong bone-metal interface. ${ }^{29}$ However, it was also noticed that tantalum spinal implants can produce a large amount of streaking, starburst-type metal artifact on the CT imaging under standard clinical settings. ${ }^{30,31}$ The image distortion, therefore, intervenes in the radiographic assessment of bony ingrowth and surrounding segmental structures. No substantial artifacts were observed in MR imaging.

Titanium alloy consisting of titanium, aluminum, and vanadium (Ti-6Al-4V) shows a comparable amount of artifact on magnetic resonance imaging, but provides much clearer images in computed tomographic scans. ${ }^{30,31}$ In the current study, we were able to fabricate porous Ti-6Al-4V OS cages with designed topology optimized features by the SLM process. The internal architecture can be clearly viewed from the micro-CT imaging without artifactual distortion, suggesting that the segmental integrity and the bony ingrowth of the construct can be assessed after surgery. With these advantages to acquire high-quality examination of imaging modalities, the porous Ti-6Al-4V OS cage demonstrates a better option as a porous metallic implant for spine fusion, compared to porous tantalum cages with the aspect for patients' follow-ups.

The porous titanium alloy Ti-6Al-4V OS cages fabricated by SLM process also gave consistent mechanical properties. The average elastic compressive modulus is $2.97 \pm 0.09 \mathrm{GPa}$, which is comparable with the reported porous tantalum modulus of 3 GPa and falls between that of cortical bone (15 GPa) and trabecular bone $(0.1 \mathrm{GPa}){ }^{32}$ The actual compressive modulus of the fabricated cage was lower than the computationally predicted modulus. This may be attributed to the slight disparity of the reproduced microstructures from the design. Even though most of the design features remained intact after the fabrication, the topological distribution of material was not perfectly identical with the original design. We know that the bulk properties of the design are the overall expression of individual microstructures. Therefore, the global properties are sensitive to the proximity of the manufactured microstrucutures to the designed ones, as well as to the reciprocal microto-micro and micro-to-macro structural interactions. Nonetheless, the design still gives a consistent layout for material deposited by SLM. Even though there was difference of material properties for the fabricated cages from the design, the properties of individuals remained very similar.

Porous tantalum, however, even though it has good mechanical properties, experiences significant deviations in the properties because of the variability of the foam structure and carbon strut dimensions coupled with variability in the layers structure and thickness due to the random pore distribution and interconnectivity generated by CVI process.

In general, metallic biocompatible materials are still a preferable in high load bearing sites like fusion cages in spine arthrodesis and acetabular cups in hip arthroplasty. However, the high stiffness of these materials compared to surrounding tissues will induce unfavorable complications related to the stress-shielding. Porous metal, such as porous tantalum, decreases the strength and stiffness dramatically by creating highly porous structures. The new techniques of integrated topology optimization design approach and SLM process are introduced in the present study as an option to create porous metallic implants with more precise control over mechanical properties that meet the requirements from various applications, for example, the aforementioned titanium alloy OS cage for interbody fusion. The design domain can be defined with arbitrary shapes according to the implant size, anatomic geometry, and/or disease/injury requirement. 
In all, the titanium alloy OS cage presents comparable stiffness to porous tantalum, providing sufficient compressive strength without excessive stiffness for maintaining spine segmental integrity. It is also better for $\mathrm{CT}$ imaging providing fewer artifacts than porous tantalum. Future work of biomechanical testing on spine segments and preclinical in vivo studies are warranted to investigate the efficacy of the proposed titanium-based spinal fusion device.

The authors thank Mr. Ali Kasemkhani and Ms. Colleen Flanagan for help in mechanical testing, and Ms. Erin Wilke and Ms. Leena Jongpaiboonkit for micro-computed tomographic (micro-CT) scan and scanning electron microscopy (SEM).

\section{References}

1. Brantigan JW, Steffee AD. A carbon fiber implant to aid interbody lumbar fusion. Two-year clinical results in the first 26 patients. Spine 1993;18:2106-2107.

2. Kuslich SD, Ulstrom CL, Griffith SL, Ahern JW, Dowdle JD. The Bagby and Kuslich method of lumbar interbody fusion. History, techniques, and 2-year follow-up results of a United States prospective, multicenter trial. Spine 1998;23:1267-1278. Discussion 1279.

3. McAfee PC, Regan JJ, Geis WP, Fedder IL. Minimally invasive anterior retroperitoneal approach to the lumbar spine. Emphasis on the lateral BAK. Spine 1998;23:1476-1484.

4. Ray CD. Threaded titanium cages for lumbar interbody fusions. Spine 1997;22:667-679. Discussion 679-680.

5. van Dijk M, Smit TH, Burger EH, Wuisman PI. Bioabsorbable poly-L-lactic acid cages for lumbar interbody fusion: Threeyear follow-up radiographic, histologic, and histomorphometric analysis in goats. Spine 2002;27:2706-2714.

6. van Dijk M, Smit TH, Sugihara S, Burger EH, Wuisman PI. The effect of cage stiffness on the rate of lumbar interbody fusion: An in vivo model using poly(L-lactic Acid) and titanium cages. Spine 2002;27:682-688.

7. van Dijk M, Tunc DC, Smit TH, Higham $\mathrm{P}$, Burger EH, Wuisman PI. In vitro and in vivo degradation of bioabsorbable PLLA spinal fusion cages. J Biomed Mater Res 2002;63:752-759.

8. Weiner BK, Fraser RD. Spine update lumbar interbody cages. Spine 1998;23:634-640.

9. Kanayama M, Cunningham BW, Haggerty CJ, Abumi K, Kaneda K, McAfee PC. In vitro biomechanical investigation of the stability and stress-shielding effect of lumbar interbody fusion devices. J Neurosurg 2000;93:259-265.

10. Cunningham BW, Ng JT, Haggerty CJ. A quantitative densitometric study investigating the stress-shiedling effects of interbody spinal fusion devices: Emphasis on long-term fusions in thoroughbred racehorses. Trans Orthop Res Soc 1998;23:250.

11. Laftman P, Nilsson OS, Brosjo O, Stromberg L. Stress shielding by rigid fixation studied in osteotomized rabbit tibiae. Acta Paediatrica Scand Suppl 1989;60:718-722.

12. Tonino AJ, Davidson CL, Klopper PJ, Linclau LA. Protection from stress in bone and its effects. Experiments with stainless steel and plastic plates in dogs. J Bone Joint Surg Br 1976;58: 107-113.
13. Bobyn JD, Stackpool GJ, Hacking SA, Tanzer M, Krygier JJ. Characteristics of bone ingrowth and interface mechanics of a new porous tantalum biomaterial. J Bone Joint Surg $\mathrm{Br}$ 1999;81:907-914.

14. Zardiackas LD, Parsell DE, Dillon LD, Mitchell DW, Nunnery LA, Poggie R. Structure, metallurgy, and mechanical properties of a porous tantalum foam. J Biomed Mater Res 2001;58:180-187.

15. Shabalovskaya SA. Surface, corrosion and biocompatibility aspects of Nitinol as an implant material. Biomed Mater Eng 2002;12:69-109.

16. Lin $C Y$, Hsiao CC, Chen $P Q$, Hollister SJ. Interbody fusion cage design using integrated global layout and local microstructure topology optimization. Spine 2004;26:1747-1754.

17. Bendsoe MP, Kikuchi N. Generating optimal topologies in structural design using a homogenization method. Comput Methods Appl Mech Eng 1988;71:197-224.

18. Kikuchi N. Design optimization method for compliant mechanisms and material microstructure. Comput Math Appl Mech Eng 1998;151:401.

19. Arora JS, Haug EJ. Methods of design sensitivity analysis in structural optimization. AIAA J 1979;17:970-974.

20. Suzuki K, Kikuchi N. A homogenization method for shape and topology optimization. Comput Methods Appl Mech Eng 1991;93:291-318.

21. Hollister SJ, Maddox RD, Taboas JM. Optimal design and fabrication of scaffolds to mimic tissue properties and satisfy biological constraints. Biomaterials 2002;23:4095-4103.

22. Lin C, Kikuchi N, Hollister SJ. A novel method for internal architecture design to match bone elastic properties with desired porosity. J Biomech 2004;37:623-636.

23. Lin CY, Hsiao CC, Chen PQ, Hollister SJ. Interbody fusion cage design using integrated global layout and local microstructure topology optimization. Spine 2004;29:1747-1754.

24. Hollander DA, von Walter M, Wirtz T, Sellei R, SchmidtRohlfing B, Paar O, Erli HJ. Structural, mechanical and in vitro characterization of individually structured Ti-6Al-4V produced by direct laser forming. Biomaterials 2006;27:955963.

25. Annual Book of ASTM Standards. Medical devices and services, Section 13, Vol. 13.01, 2004.

26. Black J. Biological performance of tantalum. Clin Mater 1994;16:167-173.

27. Lewis RJS. Hawley's Condensed Chemical Dictionary, 12th ed. Ban New York:Nostrand Reinhold; 1993.

28. Lide DR. CRC Handbook of Chemistry and Physics, 76th ed. Boca Raton, FL:CRC Press; 1995.

29. Pfluger G, Plenk H, Bohler N, Grandschober F, Schider S. Experimental studies on total knee and hip joint endoprosthesis made of tantalum. In: Winder GD, Gibbons DF, Plenk HJ, editors. Biomaterials. Chichester: Wiley; 1980. p 161-167.

30. Levi AD, Choi WG, Keller PJ, Heiserman JE, Sonntag VK, Dickman CA. The radiographic and imaging characteristics of porous tantalum implants within the human cervical spine. Spine 1998;23:1245-1250. Discussion 1251.

31. Wang JC, Yu WD, Sandhu HS, Tam V, Delamarter RB. A comparison of magnetic resonance and computed tomographic image quality after the implantation of tantalum and titanium spinal instrumentation. Spine 1998;23:1684-1688.

32. Wigfield CC, Robie BH. Porous tantalum for spinal interbody fusion. In: Lewandrowski KU, Wise DL, Trantolo DJ, Yaszemski MJ, White AA, editors. Advances in Spinal Fusion. Basel, NY: Marcel Dekker; 2004. p 775-781. 